shown that the thyroid is the outpost of the defensive organic army of healthy nutrition. As Hertoghe has stated, "All the great causes of pathological disturbance, tuberculosis, syphilis, alcoholism, paludism, chronic starvation, consanguinity, etc., aim their first blow at the thyroid."* The admission, therefore, is unavoidable that thyroid therapy cannot be regarded as a "fad," liable at any time to be cast aside as a discredited fashion. Every day additional knowledge is being gained of its beneficent reality, and no one in these' days can afford to neglect its teaching. Hertoghe's forecast, therefore that "the day is coming when we will interrogate the thyroid equation (hypo- or hyper-) in all our patients with the same fidelity that we inquire into their previous history, in respect to tuberculosis, syphilıs, and alcoholism," may come to be realized in practice. The old common saying " a man is as old as his arteries" is sadly, out of date. Its misconception lies in its recognition of effects rather than of causes. A truer axiom would be "a man is as old as his thyroid," for it is the thyroid, as the regulator of nutrition, which keeps an old man; with vigour of mind and body, young, by counteracting auto-intoxication-Metchnikoff's theory of the cause of old age. It is the thyroid, too, which prevents and controls the advent and progress of arterio-sclerosis. Oftentimes dulness of spirit and a disturbing melancholy, irrepressible by volitional effort, are of toxaemic, and not of psychological origin : in such cases by stimulating a tired thyroid, the buoyancy of life is restored, and the mist-clouds of despondency dispersed. Finally, if thyroid therapy fails to yield the miracles expected of it after due trial, that is proof that the gland is in no need of assistance.

\title{
CURIOUS RESULT OF EXPLOSION INJURY TO EYE
}

BY

W. A. Anderson, Capt. R.A.M.C.

Eye examination of Pte. B-, March 20, 1917.

Two and a half years ago, whilst in the north island of New Zealand, he lit in a fire a roll of paper which, unknown to him, contained a tin of detonators. These exploded, and he was knocked over and wounded in several places, and a very small fragment entered the right eye, as the result of which he states he was blind for several days afterwards.

$R$. eye. To the nasal side of cornea, in the horizontal plane, there is a small, dark spot ; ? point of entry of foreign body.

\footnotetext{
"American Medicine, April, 1914.
} 
$R$. cornea. Upper half of cornea shows fine keratitis, and from the centre of the cornea, stretching downwards and inwards, there is an irregular line-like opacity.

Iris is the same colour as that of the left eye and dilates regularly under homatropin.

Lens. Anterior lens capsule shows a distinct negative photograph of iris; the pupil can be recognized and is 2 to $2.5 \mathrm{~mm}$. in diameter. Immediately around the pupillary area the impression on the anterior lens capsule is dense, and radiating outwards are many bands of similar density.

Vitreous shows many opacities, with one more solid than the rest close to posterior surface of lens.

Vision: R.E. 6/12 and reads Sn. 0.6.

L.E. $6 / 6$ and reads Sn. 0.5.

Refraction, under mydriatic :

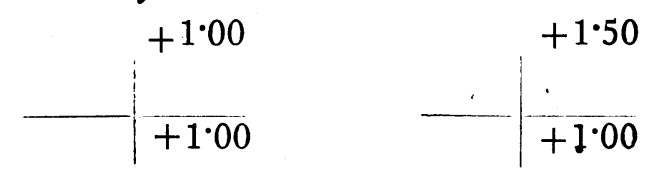

Shadows are somewhat irregular in the right eye. Pupils active. Tension normal. No fundus changes seen. X-ray negative.

L. eye, normal.

I am unable to account for the changes as described. They form a beautiful picture, and the whole, as I have said, is a splendid "negative photograph" of the iris.

Some change must have taken place inside the eye, between the foreign body and the fluids of the eye, producing some substance which combined with the pigment of the iris to form on the lens capsule a photograph as described.

No other colour changes were found in the eye.

\title{
INTRA-CRANIAL SARCOMA, WITH EARLY SYMPTOMS OF ACUTE RETRO-BULBAR NEURITIS
}

\author{
BY \\ H. H. MCNabB, M.D., Ch.B. (Vict.). \\ HON. SURGEON MANCHESTER ROYAL EYE HOSPITAL, ETC.
}

ON August 3, W. R., æt. 16, was sent to me by Dr. Barritt. He complained of vision in the left eye being blurred for one week and getting worse two days before I saw him. There was periorbital aching and slight pain on movement of the eye, and also when the eye was pushed backwards.

Vision R. 5/4. L. Fingers. Fundi normal. 